\title{
Costs of land degradation and benefits of land restoration: A review of valuation methods and suggested frameworks for inclusion into policy-making
}

\author{
Emmanuelle Quillérou ${ }^{1}$ and Richard J. Thomas ${ }^{1 *}$
}

Address: ${ }^{1}$ United Nations University - Institute for Water, Environment and Health, 175 Longwood Rd. South, Suite 204, Hamilton, Ontario L8P 0A1, Canada.

* Correspondence: Richard J. Thomas. Email: Richard.Thomas@unu.edu

This is a pre-copy-editing, author-produced PDF of an article accepted for publication in CAB Reviews: Perspectives in Agriculture, Veterinary Science, Nutrition and Natural Resources following peer review.

Quillérou, E., Thomas, R.J. (2012) Costs of land degradation and benefits of land restoration: A review of valuation methods and their application. CAB Reviews: Perspectives in Agriculture, Veterinary Science, Nutrition and Natural Resources, 7 No 0606. Available from: http://www.cabi.org/cabreviews

\section{Abstract}

Land degradation has become a growing concern with the current increase in demand for arable land. Sustainable land management and land restoration practices are required in order to meet the demands to provide food and other services. Adoption of improved practices has however not been widespread partly due to a lack of clarity on the true economic value and setting of proper financial incentives. This article focuses on the economic costs of land degradation as a prelude to two on-going initiatives involving the United Nations Convention to Combat Desertification (UNCCD). We review how ecosystem services derived from land have been economically valued to date. Economic valuation has mostly focused on the use value of provisioning services and cultural services, with limited valuation of non-use value of cultural services. Also, no unique valuation method has been applied following methodological developments, varying study objectives and data availability constraints. These factors impair coherent and consistent estimation of the total economic value of land degradation across 
countries. We identify a need to develop harmonised valuation methods to estimate total economic value under strong data and capacity constraints. We propose two alternative frameworks for harmonised total economic valuation of land degradation at country-level to guide further research in making environmental valuation more relevant and practical under strong data and capacity constraints. Keywords: land restoration, economic valuation, ecosystem services, limited data, limited capacity

Review methodology: We started off from existing reports on land degradation and ecosystem valuations (Winslow et al., 2011, Millennium Ecosystem Assessment, 2005). We also reviewed existing economic reviews by Nkonya et al. (2011), Adhikari and Nadella (2011), Requier-Desjardins (2006), Requier-Desjardins et al. (2011). In addition, we searched the following database and journals: Google Scholar, Land Degradation \& Development, Journal of Agricultural and Resource Economics, Journal of Environmental Economics and Management, Environmental and Resource Economics, Ecological Economics (keyword search terms used: land degradation, cost of land degradation, economic valuation, economic valuation and developing country, payments for ecosystem services, payments for ecosystem services and developing countries). We used the references from the articles obtained by this method to check for additional relevant material. We also spoke to colleagues and checked for any upcoming studies not yet published. 


\section{Introduction}

This article aims to identify general ideas and frameworks for including environmental considerations in policy-making. This serves as a prelude to two on-going initiatives involving the United Nations Convention to Combat Desertification (UNCCD). The first is the second scientific conference of the UNCCD to be held in 2013 on the topic of the "Economic assessment of desertification, sustainable land management and resilience of arid, semi-arid and dry sub-humid areas" (1) and the second is a global initiative on the economics of land degradation organised by the German Federal Ministry for Economic Cooperation and Development, the European Commission, the UNCCD amongst others (2). Both these initiatives aim to further increase awareness of the potential for socially desirable action to restore land in critical areas and to prevent further land degradation.

Land, including water, is under pressure from a large number of interacting factors such as population growth and associated food security concerns, over use and degradation, competition between food, biofuel production and conservation, and increasing policy drives towards carbon sequestration. An estimated 6 million hectares of land will need to be brought into agricultural production every year up to 2030 in order to meet the food demands of a growing population if productivity remains at current levels (3) and up to 1 billion hectares of land would need to be cleared globally by 2050 with continuing extensification strategies in developing countries (4). This demand is resulting in the search for land beyond the borders of emerging economy countries in order to fulfill their food, water and energy needs. As much as 80 million hectares of land may already be leased or otherwise negotiated with a foreign investor (5). Often these negotiations also involve water rights and access (6).

Currently there is little or no regulation over these 'land deals' resulting in calls to establish sets of principles for responsible land governance, enabling institutions and investments $(7,8)$. Concern has been expressed that customary rights to land access and use are often 'short-changed' in land deals, 
meaning inadequate compensation for customary users' loss of the use of land and particularly where direct values from land may provide as much as $90 \%$ of the livelihoods of rural populations, e.g. in much of Sub-Saharan Africa (9). A recent article in Guardian's Global Development site stressed the growing tension between stakeholders and investment companies in Sierra Leone (10). Farmers receive $\$ 5 /$ ha/year from a plantation investor under a 50 -year contract. This payment is however perceived as "unacceptable" as it does not fully compensate farmers for the loss of "valuable trees and plants destroyed in the clearing of the land", or more specifically for the loss of services previously provided by these trees and plants. This perceived unfairness led to social unrest and demonstrations last year, turning what could be a win-win situation in a lose-lose one. Such contestation can deter foreign investors and limit further opportunities for development.

This is a typical case of information asymmetry, with government or investors not appreciating fully land values that have not been quantified in monetary terms. Hence better economic valuation of land, by quantifying explicitly the benefits derived from land, could provide a basis for fairer financial compensation for those displaced from, or dispossessed of land they have used. Better economic valuation would also help better balance negotiating powers between stakeholder groups by increasing transparency over the level of compensation to be provided.

In addition to competition for land, the loss of perhaps 0.7 to 2 billion hectares of agricultural land through degradation that continues mainly unabated $(11,12)$ is driving the urgency to monitor and assess the economic losses associated with degradation $(13,14)$. Thus as per capita arable land shrinks from around 0.5 ha in the 1960 s to a predicted 0.15 ha in 2050 (15), it is imperative that the value of land is recognised and that the costs of inappropriate use and degradation are widely known together with the benefits of restoring and maintaining land productivity.

There is adequate scientific knowledge on how to prevent and/or reverse land degradation (eg., 16 , 17). However this knowledge has not been widely adopted partly because policies for investing in 
sustainable land management are not perceived as priorities when national budgets are allocated across sectors. Much has been written about this lack of investment in combating land degradation or in the converse, sustainable land management, with insufficient attention paid to the required financing strategies needed at local, national and international scales (18). Two main reasons have been identified for this lack of investment by national authorities. Firstly, there is the lack of information on the true economic costs of land degradation (or benefits of sustainable land management) available to policymakers. This has limited the identification of areas where investment would be socially desirable. Secondly, the local stakeholders affected by land degradation do not have the necessary knowledge or means, including financial, to make their case at the national level. Similarly they often cannot enforce their property rights over the land they use when they have them. These factors result in low lobbying and negotiation powers of local stakeholders. A better estimate of the true value of land to society would help policy-makers clarify the level of benefits to be derived and lead to a better identification and choice of land use options. Valuing land would increase transparency in the negotiation and compensation process thereby potentially leading to a more balanced and "fair" negotiation over land issues between the different stakeholders.

Thus from a number of perspectives there is a timely need to re-assess the value of land to help both decision makers and land use practitioners assess current and future land use practices and to enable analyses of the trade-offs associated with different land use patterns. This review builds on an earlier report that recognised the need to value the land in ways that include both economic and noneconomic values (19).

The purpose of this article is to review existing information, identify the gaps and propose frameworks with tools to be used by national governments to enable a better economic valuation of land as a key natural resource. We aim to identify potential alternative frameworks for economic valuation of land services that could be easily implemented in practice at country level under limited 
data availability and human and institutional capacity. The two alternative frameworks proposed in this article have been identified so as to provide a guide to policy-makers for inclusion of land valuation into policy-making. The article attempts to move beyond existing studies on the valuation of land degradation that have focused on the direct use value of provisioning services, and more specifically on the loss of agricultural productive capacity (20), by including non-use values explicitly.

We also call for a harmonised approach to land valuation for two reasons. Firstly a harmonised approach to valuation would make values more directly comparable between different areas and countries. Secondly advocating a harmonised approach to valuation to governments could facilitate adoption of land valuation by these governments as well as lend itself to peer cross-country learning and training.

This article starts by detailing the general context for interest in the land degradation problem, then describes the economic framework considered for valuation of land services, briefly reviews case studies to identify the valuation methodologies used for each type of ecosystem services provided, and methods for deriving the total economic value from these individual service values. Some limitations of the framework for valuing land degradation are described and we then propose two practical alternatives for economic valuation of the costs of land degradation. We conclude with a discussion on the need for increased harmonisation in the valuation methods and their application where data and capacity are limited and the need to link this with capacity building.

\section{Estimating a Total Economic Value of land degradation}

\section{Valuation framework}

The full costs of land degradation are difficult to measure but are thought to be substantial and growing (21). In this review, we adopt a total economic value approach as the basis for a cost-benefit analysis of land restoration at country-level. This cost-benefit analysis of land restoration would 
compare the total economic benefits of land restoration to the economic costs of restoring degraded land. The economic costs of land restoration (or cost-side of the analysis) correspond to costs associated with action to restore degraded land, for instance the costs of adopting sustainable land management practices. The total economic benefits of land restoration (benefit-side of the analysis) correspond to benefits that would be derived from improving degraded land to a restored state. A cost-benefit analysis of land restoration should help to identify whether land restoration would be socially beneficial at the national level. This would provide a rationale for provision of relevant policy instruments for improved uptake of sustainable land management practices. The costs and benefits of restoration depend implicitly on the level of land degradation because the cost-benefit analysis requires a baseline scenario for assessment of the social acceptability of changes.

This cost benefit analysis needs to be undertaken at the national level rather than on a series of "hot spots" or specific areas. The success of hot spot conservation has been shown to depend on the state of the countryside surrounding it (22). Hot spot restoration would thus need to be supplemented by a wider scope approach for greater (cost-)effectiveness. We could envisage a two-tiered approach to land restoration, combining a first tier of low level restoration available at the national level with a second tier of higher level of restoration for targeted "hot spots". This two-tier approach would still require a national-level analysis.

Estimation of a total economic value would be feasible for preliminary larger scale assessments. For vast countries, regional sub-country levels could be considered for valuation as the most appropriate level of analysis. Total economic valuation implicitly assumes that land will be restored to $100 \%$ of its potential, which might not be the case depending on the specific context. Also, local-level assessments are likely to include a broader range of services from land that need to be valued. A cost-benefit analysis for partial restoration might be more appropriate and less costly than a full total economic valuation at the local level, depending on specific study contexts. 
The rest of the article focuses on the benefit-side of the analysis with the estimation of the potential benefits of land restoration currently foregone because of land degradation. These forgone benefits represent a cost to society associated with inaction, and depend on the level of land degradation. The potential benefits from land restoration (arrow 2 in Figure 1) correspond to the cost of land degradation (arrow 1 in Figure 1). The difference is that these expressions do not stress the same direction of change in land state as illustrated in Figure 1.

\section{Insert Figure 1 about here}

Total economic value is conceptually defined as the sum of the use and non-use values of a good or service. Use value can be further decomposed into direct and indirect use values, and non-use value into option and existence or bequest values. Option value is the value given by society on keeping options open. Existence value is given to goods that are not used but simply to acknowledge that their existence has a value, and bequest value relates to the value given to the transfer of a given good to future generations. This typical theoretical framework for economic valuation is detailed more specifically in Nkonya et al. (23). To derive the total economic value of land, we allocate a value to services derived from land. The costs of land degradation are measured as the loss of ecosystem services (or opportunity costs) as implicitly compared to a fully restored land. These opportunity costs constitute a measure of the benefits foregone when land is degraded i.e. the extra benefits that would be derived if land were fully restored. For mutually exclusive ecosystem services, the total economic value is the (socially weighted) sum of the total economic values of each of these services.

The following ecosystem services have been identified by the Millennium Ecosystem Assessment (24): provisioning services (food, timber and fresh water), regulating services (pollution), cultural services (aesthetic and spiritual values) and supporting services (soil formation, nutrient cycling). To 
derive a total economic value, these services are assumed mutually exclusive i.e. there is no joint production between services. Table 1 relates each of these ecosystem services to the type of economic value that can be used to characterise these services. This classification of ecosystem services has been adopted for valuation studies but has been adapted to the study context so as to avoid double counting when services are not as independent as assumed by the Millennium Ecosystem Assessment. For instance, Dominati et al. (25) outlined that supporting services are not services as such but rather processes underlying the provision of ecosystem services, and therefore cannot be valued as such. Also, the level of nitrogen pollution is often linked to agricultural inputs and production, which means that regulating services are not always independent from provisioning services either. In theory summing up the economic values of provisioning, regulating and cultural services should give the total economic value of land. In practice however, the specific context of the study will guide which services are to be considered for economic valuation to effectively avoid double-counting.

\section{Insert Table 1 about here}

Because the ecosystem services derived from land are assumed mutually exclusive in the Millennium Ecosystem Assessment framework, we describe the methods used for their economic valuation separately in the following sections. We then describe how these values could be aggregated to derive a total economic value for land degradation and briefly discuss their degree of independence. We also describe studies that attempt to transfer estimated economic values to other sites. Building on the review by Adhikari and Nadella (26) on soil erosion, we do not review the valuation methods as extensively but rather focus on the valuation of the different types of land degradation services. Thus the article adopts a broader scope than Bojö's (27) and Adhikari and Nadella's (26) by considering case studies for a broader range of services provided by land than soil erosion prevention. A previous article 
by Requier-Desjardins et al. (13) assessed the valuation methodologies and potential economic instruments for a more economically efficient land management. Ferraro et al. (28) conducted a review of valuation studies of (provisioning and regulating) ecosystem services of forests in developing countries. They concluded that valuation of ecosystem services is rare, use various methodogies and and disconnected from policy. We complement these previous articles by focusing on the valuation of the costs of land degradation for various types of ecosystem services to derive pragmatic alternatives for harmonised valuations.

Noel and Soussan (29) proposed a multi-level methodology for cost benefit analysis of ecosystem services, with 6 key steps: (i) inception, (ii) identification of land covers, (iii) analysis of ecosystem services, (iv) role of these services in livelihoods and economic development, (v) identification of land degradation patterns and pressures, and (vi) assessment of sustainable and suitable land management options. This review relates to the third step of their framework with the role of ecosystem services valued in economic terms.

\section{Measuring the total economic value of provisioning services}

Provisioning services from land include food and fodder, fresh water supply, fibre and fuel (timber, wool), biochemicals, natural medicines and pharmaceuticals, genetic resources (breeding), ornamental resources (shells, flowers), housing and urban development. These provisioning services are typically valued based on direct use value and option (non-use) value derived from possible future usage. These values are measured by productivity changes, replacement costs, reduced costs because of mitigative behaviour or costs of extreme events such as crises and famines. These valuation methods are all based on the supply of land services. Economic valuation studies have mostly focused on the costs of soil erosion because it is visible in the short term and more easily quantified in developing countries $(26,30)$. The costs of soil erosion considered in these papers relate to the loss of agricultural 
productivity because of soil erosion rather than the costs of silting up waterways and reservoirs (i.e. a regulating service).

Productivity losses are mostly on-site costs borne by farmers measured as the losses in agricultural income. For instance, soil erosion will cause agricultural yields and farmers income to decrease. This reduced agricultural income from soil erosion in this context represents the cost of land degradation. The costs of land degradation are estimated using production models which link levels of land degradation (such as soil erosion) with quantities of agricultural outputs (yields). This methodology has been applied in Mali (31), in Sri Lanka (32), the Philippine Uplands (33, 34), Ethiopia (35, 36), Zimbabwe (37) ${ }^{1}$. Estimates of the aggregate costs of soil erosion in these countries however varies considerably, by 10 to 100 fold depending on the study conducted (26). Production-based approaches seem popular for valuation in developing countries where agricultural production data is relatively available or easy to obtain.

A similar method consists in valuing the costs involved in replacing the lost service. For instance, soil erosion will lead to a loss of soil nutrients that can be compensated by using an increased quantity of fertiliser. This increased usage of fertiliser has a cost to farmers, which represents the cost of mitigating the loss of nutrients from soil erosion or cost of the land degradation considered. This approach has been applied in Zimbabwe (38), for a range of Sub-Saharan African countries (39), in the Puentes Catchment of Southern Spain (40) and in Mali (41). Pimentel et al. (36) adopted a more complete approach by considering both soil quality variables and water resources in addition to wind and soil erosion to derive costs of soil erosion for the United States. This method overestimates the contribution of nutrients to soil degradation because its focuses on a specific input for production rather than a bundle of substitutable inputs $(23, \mathrm{p} 73)$. It tends to produce slightly lower cost estimates than the change in productivity method (26).

\footnotetext{
${ }^{1}$ All these studies are reviewed in details in Adhikari and Nadella (2011).
} 
The above production-based approaches tend to ignore the trade-offs between production inputs (such as erosion and fertiliser) for a given output quantity (yield) ${ }^{2}$. This is a problem for deriving representative estimates of the costs of land degradation. Also, erosion is not the only land degradation process reducing food production. This type of approach thus tends to overestimate the true economic cost of one land degradation process whilst underestimating the true overall economic cost of land degradation. The production-based approach also relies on crop market prices which could lead to estimation biases because of poorly developed or distorted markets (42). Estimating production models can be very data-consuming and tend to be done at the farm level because of site-specificity, which limits the validity of using the cost estimates for other sites (23, p.74-75).

Ngugi et al. (43) used a form of participatory environmental valuation to value different uses made of a drylands forest in Kenya. They used the contingent valuation method which is based on demand for land services, rather than supply as for the production-based approaches described above. Contingent valuation is a method based on asking people how much they would be willing to pay (or accept) for an environmental improvement (degradation) to then derive a demand curve. This method can capture the total economic value of the goods and services considered. Ngugi et al. asked the local communities to state how much they value their non monetary uses of the forest. They found that the most valued local forest use by local communities is the collection of traditional medicinal plants, amounting to 7 to over $10 \%$ of household's annual income. Because of the nature of the services involved, this study estimated the use value of these goods, rather than both use and non-use values of the forest to local residents.

\footnotetext{
${ }^{2}$ This is a problem that is not unique to production-based approaches and is raised in further sections of this article.
} 


\section{Measuring the total economic value of regulating services}

These services encompass pollution regulation for air and water, climate regulation with carbon sequestration, natural hazard protection (e.g., storms, floods and landslides). Most of these services can be valued by replacement costs, the costs of cleaning up pollution or the damage costs incurred because of an extreme event. These values for land degradation mostly fall under indirect use and option values. These services typically include off-site impacts of land degradation whose benefits or costs are borne by third parties (externalities). The main regulating service considered in the academic literature has been carbon sequestration (climate regulation) partly because of the prominence of the climate change debate and partly because the costs of cleaning-up pollution and extreme events can be more directly measured. Valuing carbon sequestration relies on estimating the quantity of carbon sequestrated and multiplying it by the market price for carbon. For instance, Antle et al. (44) established a model of ecosystem service supply from agricultural land, similar to a productivity approach where ecosystem services are included as one of the outputs from agriculture. They applied it to estimate soil carbon sequestration in semi-subsistence farming systems in Kenya and Senegal. Similarly, Mekuria et al. (45) estimated soil nutrient run off reduction and soil carbon sequestration by taking soil samples in representative exclosures (areas set aside for regeneration) in Ethiopia. They then used the market prices for carbon and nutrients to estimate the benefits from land restoration.

\section{Measuring the total economic value of cultural services}

Values for cultural services include aesthetic values, values derived from recreation and tourism, cultural heritage (e.g. indigenous knowledge) or spiritual values (e.g. religious values given to ecosystems). These values typically encompass direct use values, option values and/or non-use values. Aesthetic values, values derived from recreation and tourism have so far been the main values of interest in the academic literature but with little application in developing countries. 
Aesthetic, recreational and tourism values are mostly derived using revealed preference methods such as hedonic pricing and the travel cost method, or stated preference methods such as contingent valuation and choice modelling. The principle behind hedonic pricing is to derive a value from an existing market price e.g. property, land. However this method relies on well functioning land markets, which might not exist in developing countries (46). Stated preference methods involve people stating how much they would be willing to pay for conservation (or willing to accept for degradation) of a specific service. Contingent valuation asks people straightforwardly how much they would be prepared to pay. Choice modelling is based on people choosing between alternative scenarios with different levels of environmental (or non-environmental) attributes and prices paid. This method has been developed to try and better elicit people's preferences for the environment by making explicit trade-offs between attributes or services. The derivation of aesthetic values seems more advanced in developed countries than developing countries, in line with greater environmental concerns in developed countries. For instance, Sayadi et al. (47) have shown that agricultural land in Spain has aesthetic value for agrotourism in the region. Stated preference methods are the most advanced for capturing total economic value but are relatively data intensive. The value of existing activities such as ecotourism, national parks or UNESCO World Heritage Sites (e.g., entry fees) could also be used as a basis for recreational values where these already exist (48).

The value of cultural heritage and the spiritual values for land and their associated ecosystems have not yet been subject to a specific estimation in the economic literature. Ngugi et al. $(43$, p.170) specify that the people they interviewed did not want to place a value on the forest used for cultural purposes and rituals but rather stated that the community sages would be better placed for this type of valuation. 


\section{Measuring the total economic value of supporting services}

These values encompass the values of primary production, nutrient cycling and run off, soil formation and erosion. They are mostly private costs to landowners or land users. Hedonic pricing could be used to value the status of on-farm conservation works (i.e. the state of the land) from land prices but this would require active undistorted land markets (46). Supporting services refer however more to processes rather than actual services (as outlined by 25). Consequently these "services" would be best measured through the valuation of the ecosystem services described previously rather than on their own, to avoid double counting.

\section{Putting a value on a bundle of services or aggregating individual values}

All the above services are assumed to be independently produced following the Millennium Ecosystem Assessment framework. Birch et al. (48) derived a value for dryland forest restoration by estimating the values of several ecosystem services (carbon sequestration, non timber forest products, timber, tourism and livestock production) separately before compiling these values into a scenariobased cost-benefit analysis. Crossman et al. (49) adopted a similar approach, valuing separately river salinity, carbon sequestration, food production, fresh water flows for improved ecological communities, recreation and amenity. Gascoigne et al. (50) first estimated biological quantities of ecological services provided per year and per hectare, then valued them before aggregating these values.

However, a number of studies have considered the above ecosystem services as jointly produced. For instance, agriculture has been advovated in Europe as being multifunctional, because it provides not only food and fiber but also environmental services. One frequent problem with valuation of several goods and services jointly provided is that the sum of individual service values is greater than the value of services provided as a bundle. This is because of trade-offs between services provided and could lead to a part-whole bias. This is a problem for deriving a valid total economic value of land across services 
provided (51-54). Also, summing up normalised values of ecosystem services might fail to include the value of externalities.

This problem could be overcome by estimating a total economic value of land as a whole, e.g., by using contingent valuation, rather than differentiating it per service provided. Alternatively, we could use a valuation method that takes these trade-offs into account and estimates values for both individual features and overall services. Choice modelling allows the capture of tradeoffs between different ecosystem services and could be adopted to value these services as a bundle as well as individually (55). This approach has been successfully tried for economic valuation of water-intensive agriculture impacts on rivers and streams in New Zealand compared to those of dryland pastoral and arable farming (56). The three impacts valued are increased health risks of pathogens from animal waste, degraded ecological quality from excess nutrients, increased number of low-flow months because of increased irrigation, which correspond to regulating and cultural services.

Another solution is to assign weights to individual components for aggregation. These weights can be derived using multi-criteria analysis, basically a form of scoring reflecting social preferences. This approach has been used mostly for selection of areas or farms for allocation of conservation contracts with benefits quantified but not necessarily valued in monetary terms (57). This multi-criteria analysis can be combined with geographical data for aggregation of values that are spatially heterogeneous (5861).

\section{Transferring economic values of different goods and services to other sites}

Benefit transfer is one of the most interesting areas for development and integration of environmental valuation into policy-making. Benefit transfer has developed in relation to values related to demand for (rather than supply of) ecosystem services. This method explicitly consists of transferring values across time, space, population and in some occasions across ecosystem goods (62) from a site 
that has been monetarily valued to a site that has not yet been monetarily valued. Economic valuations tend to be costly in terms of financial, time and human resources and benefit transfer offers a cheaper alternative to other valuation methods. Benefit transfer shows clear potential for transferring land service values to other areas of interest by controlling for variation from the area that has been valued to the area of interest. It has been designed as a pragmatic and cost-saving method that could be easily used for informed policy-making under strong data and capacity constraints.

Benefit transfer sometimes simply consists in an extrapolation of the economic values obtained by other valuation methods. The design of the choice modelling method allows the derivation of normalised values for ecosystem services that can then be scaled up as required. Choice modelling thus provides a good basis for benefit transfer. In addition, benefit transfer of values across space has been facilitated by the development of Geographical Information Systems (GIS) $(58,63)$. However, estimated unit values theoretically depend on absolute levels of provision (scale and scope), which could limit the relevance and accuracy of benefit transfer.

Meta-regression models have also been used to transfer values by controlling for some of the main factors of variation such as income levels. These models can be based on Bayesian modelling, which has been shown to lead to accurate estimates even for small underlying meta-samples (64). In practice however, the required adjustment factors for benefit transfer depend on the change in scale considered. It has been shown that adjustments might be required for benefit transfer between different countries (65) but not necessarily between the national and the regional scales (62).

Despite its theoretical appeal and potential, benefit transfer is still prone to scale and sampling effects that need to be tested for and can impair the derivation of reliable estimates of environmental values. Whether to adjust values for accurate extrapolation and how to best do so still needs to be dealt with on a case-by-case basis, which currently limits the applicability of the method especially under limited capacity. 


\section{Valuing ecosystems services in practice}

\section{Limitations of the adopted framework for valuation of land degradation}

From the previous sections, we can identify some key limitations in the derivation of a total economic value for land degradation. The different approaches detailed above depend on how the economic value is socially defined by stakeholders or policy-makers, so most of the limitations detailed below stem from this definition of the true economic value. First, studies do not always measure the same type of economic value (use value and/or non-use value) depending on the methodology used and specific study objectives. Because of this, the value of services is often not expressed in the same unit: as percent GDP, as dollars, as $\$ /$ year/ha, as $\$ /$ year/inhabitant. Also, productivity changes, replacement costs, reduced costs because of mitigative behaviour or costs of extreme events such as crises and famines are measures derived from the supply of land services. On the contrary, non-market valuation methods such as contingent valuation and choice modelling are based on the demand for land services. This could further blur what is actually measured when deriving the total economic value.

Second, the range of ecosystem services included for economic valuation also vary between studies, with most studies focusing on one type of ecosystem services for economic valuation. Very few studies have attempted to estimate the value of the full range of services (as also found by 66). Even if they did attempt to estimate the value of the full range of services, the services actually selected for valuation might change. This is to avoid double-counting and depends on the specific context of the study. Also, the definition of what constitutes the true economic value in a given context influences whether this economic value is under- or overestimated. This is a common problem for all valuation approaches.

Third, a given service can be valued very differently. The application of a given methodology is constrained by data availability and the specific case study context. This explains some of the variations in the applied valuation method and also the limited method transferability across countries (e.g. as 
outlined by 67). This is most obvious in studies on the use of several agricultural production models to value the cost of erosion. Choice modelling would seem the most advanced valuation method for estimating the value of ecosystem services. It can estimate both "part" as well as "whole" economic values but is still subject to various estimation biases (e.g. 68, 69). The application of a given methodology is also constrained by the limited human capacity for undertaking valuation (as outlined in India by 70).

Fourth, benefit transfer and aggregation of values across different ecosystem services is far from being as easy to implement in practice as theoretically suggested. A related problem is the discrepancies in the units used to express economic values (\%GDP, \$/year, \$/year/ha, \$/year/inhabitant...). Because the units are so diverse, not all values are expressed in unit terms to allow easy aggregation and scaling up. Progress has however been made with recent developments in spatial data capacities and metaanalyses. Also, economic values are typically subject to decreasing returns to scale, with the economic value of restoring a small area higher per hectare than for a larger area. Scaling up of unit economic values thus might not always lead to reliable aggregate estimates.

Fifth, the estimates also depend on the type of people surveyed (experts, residents or tourists) and their distance to the good or service valued $(54,71,72)$. Chaudhry et al. (71) also outlined the need to supplement valuation methods of stated preferences such as contingent valuation by participant observation and unstructured interviews to derive reasonable non-market estimates in developing countries with a high proportion of 'black market' or unrecorded activities and corruption.

\section{Alternatives for total economic valuation of a range of land services under limited data and capacity}

Taking these limitations into account, we can identify two potential pragmatic ways for policymakers to estimate the total economic value of land services at national level. Benefit transfer will 
become more attractive as more valuation studies are undertaken at more local levels and could then constitute a third alternative. The two alternatives considered are summed up in Table 2 . The choice between these alternatives depends on which is less costly to implement in practice considering data already available and the country's capacity to obtain reliable national estimates. Both these approaches are outlined in general terms in an attempt to provide policy makers with simple frameworks for environmental valuation they could use for more informed policy-making.

\section{Insert Table 2 about here}

The first approach consists in estimating the value of ecosystem services separately then aggregating them ("Alternative 1" in Table 2). This alternative is based on using as much secondary information as possible. The value of provision services could be estimated using productivity loss models. This method has already been used quite extensively in the literature and in limited data environments. In particular, the approach developed by Antle et al. (44) could be easily implemented in practice. The value of regulating services could be approximated by averaging public expenses for extreme events such as droughts, landslides, one-off chemical contaminations over the time period (and scale) of interest. This is obviously too simplistic and does not constitute the best economic approach for estimating the costs of regulating services. This approach could however allow the inclusion of some albeit imperfect estimate of the cost of regulating services and constitute a pragmatic first entry point for more informed policy-making. Because this is an averaged value of one-offs payments, this should not prove too difficult to estimate in practice under limited information. It might however be more relevant to compare the costs of regulating services to cleaning up costs or to the costs of prevention directly, rather than bundle them up with other types of services. This is the case if the action considered is related to managing risks of droughts or silting up of waterways rather than an indirect 
consequence of adoption of sustainable land management practices as a whole. In addition, models of carbon storage depending on climate and land uses that have been developed in the literature should also be relatively easy to apply in practice. The value for cultural services could be derived based on the value of (rural) tourism. When rural tourism value cannot be easily approximated, contingent valuation or choice modelling could be used to derive the value for cultural services, depending on the expected trade-offs between individual services. Social weights reflecting society's preferences between ecosystem services would then need to be estimated by surveying a representative sample of people. These weights would be applied to the individual service economic values to compute the Total Economic Value.

The second approach would consist in applying choice modelling to all types of services at the same time ("Alternative 2" in Table 2). This approach would allow a consideration of the trade-offs between provision services (agricultural production) with regulating (carbon storage) and cultural services (aesthetics). It would involve primary data collection and development of specific skills. This is specifically true in a developing country context where cultural and language settings can vary greatly, where respondents have lower literacy levels and are less familiar with market research surveys (73). The following factors have been stressed as critical for success of stated preference methods $(73,74)$ : primary data collection to establish the survey context, pre-testing of the questionnaire and its timing, and the use of images for illiterate respondents. Further examples and recommendations for applications of choice experiments in developing countries can be found in a dedicated book edited by Bennett and Birol (75). Contingent valuation and choice modelling, although dealing with "fictitious" money, can be used to raise awareness of the value of an environmental good and service to policymakers. This valuation could help put an actual price on the good or service considered based on its economic value to society, which in turn will increase the value of the good to policy-makers themselves. 
The choice between these two proposed alternatives depends on the level of joint production between ecosystem services (or degree of independence), already easily available data, and available capacities for non-market valuation studies. More specifically, it will depend on how costly data collection is, mainly for valuation of cultural services and derivation of the social weights (Alternative 1), compared to the cost of undertaking nation-wide choice modelling for all services (Alternative 2). Contingent valuation and choice modelling are inherently data consuming methods. It might be worth to adapt these methods to limited data contexts. Also, if local data on economic value is available, it might be useful to look into methods for scaling up these values at the national level using benefit transfer, for instance through the use of Geographical Information Systems. Perhaps more importantly, who is considered for the definition of the 'society of reference' is also one of the critical points. For national estimation of land degradation values, should national preferences or international preferences be represented? In developing countries, cultural services are notoriously considered of interest to developed countries rather than to the country providing them especially if (rural) tourism is limited. Should preferences of tourists or potential future tourists outside of the country be accounted for too? Further research and case studies would be needed to provide answers to these questions and obtain relevant and reliable values of land degradation.

\section{Conclusions}

The goal of this paper was to identify frameworks for environmental valuation of land services that can be used by policy-makers to address land issues through government policies and interdisciplinary work. Economics provides a common "measuring rod" for valuing contributions from ecosystem services derived from land from a society's point of view. This environmental valuation of land services would help assess the potential benefits from land restoration and be included in a cost- 
benefit analysis of land restoration. This cost-benefit analysis relies on a comparison between the total economic value of land degradation and the cost of restoration to assess whether it would be worth implementing policies to foster adoption of sustainable land management practices. This cost-benefit analysis would fit within the 6-step methodology for valuation project implementation proposed by Noel and Soussan (29). In this article, we focused on the benefit-side of the cost-benefit analysis of land restoration and proposed two alternative frameworks for valuation of potential land benefits across ecosystem services.

The valuation of land degradation has, so far, been mostly limited in the literature to the value of provisioning services based on losses in agricultural productivity. This is especially true in developing countries. What would be useful is to adapt the contingent valuation or choice modelling methods to limited data environment to estimate the value of cultural services. This approach would be suitable for national level estimation of the total economic value of land degradation to the country's nationals or tourists visiting the country. Capturing the non-use economic value of cultural services to other countries might however be more difficult to quantify.

What is obvious from this review is that we need international consensus on how to harmonise economic valuation methods at the national level if we are to derive comparable and reliable estimates of land degradation costs. This harmonisation of valuation methods or approaches could help make land values between countries and case studies more comparable and more easily transferable. It could also increase cross-country discussions on best practices for environmental valuations in practice and help embed valuation further into decision-making. Researchers still need to find ways to adapt the nonmarket valuation methods to limited data environments as these are so far very data intensive. The subsequent cost-benefit analysis could then be used to derive potential policy instruments to encourage socially desirable land restoration at the national level. An example of policy instrument would be 
payments for ecosystem services which represent a form of transfer of funds from beneficiaries of land services to the providers.

The two alternative frameworks proposed here are general enough to be adopted at lower-scale levels, with the level of detail for each individual valuation method to be determined from the local context. In addition to potential policy instruments, there is also a need to develop governance, knowledge management and capacity building through national networks. This might be fostered by better integrating research and policy making (28), by building a knowledge-sharing platform and an iterative network approach to pilot new valuation methods (8). We hope that this article will stimulate further work on refining existing methodologies that can help fill in the identified information gaps as well as allow for suitable implementation in countries with limited data collection capacities. This further work would be critical for the two on-going UNCCD initiatives to be successful in raising awareness on the potential for land restoration.

\section{References}

1. UNCCD. Progress report on the preparation of the UNCCD 2nd Scientific Conference and report on the organization of sessions of the Committee on Science and Technology in a predominantly scientific and technical conference-style format. 2011.

2. Nater T. Measuring the value of land: The economics of desertification, land degradation and drought. Bonn: 2010.

3. Deininger K, Byerlee D, Lindsay J, Norton A, Selod H, Stickler M. Rising global interest in farmland: can it yield sustainable and equitable benefits? Washington DC, USA: World Bank, 2011 Report Number: 59463 Contract No.: ISBN: 978-0-8213-8591-3.

4. Tilman D, Balzer C, Hill J, Befort BL. Global food demand and the sustainable intensification of agriculture. Proceedings of the National Academy of Sciences. 2011;108(50):20260-4. 
5. The Economist. The surge in land deals. When others are grabbing their land. The Economist May 5, 2011. 2011.

6. Mann H, Smaller C. Foreign land purchases for agriculture: what impact on sustainable development? New York: Department of Economic and Social Affairs, United Nations, 2010.

7. FAO, IFAD, UNCTAD, World Bank. Principles for Responsible Agricultural Investment that Respects Rights, Livelihoods and Resources. A discussion note. 2010.

8. Thomas RJ, Akhtar-Schuster M, Stringer LC, Marques Perez M, Escadafal R. Fertile ground? Options for a science-policy platform for land. Environmental Science \& Policy. 2012;16:122-35.

9. Wily LA. Nothing new under the sun or a new battle joined? The political economy of African dispossession in the current global land rush. International Conference on global land grabbing, 6-8 April 20112011.

10. Provost C, McClanahan P. Sierra Leone: local resistance grows as investors snap up land. The Guardian. 2012.

11. Oldeman LR, Hakkeling RTA, Sombroek WG. World Map of the Status of Human Induced Soil Degradation: An Explanatory Note. Global Assessment of Soil Degradation GLASOD, 1991 October 1991. Report No.: Contract No.: ISBN 90-6672-046-8.

12. Bai ZG, Dent DL, Olsson L, Schaepman ME. Proxy global assessment of land degradation. 2008;24(3):223-34.

13. Requier-Desjardins M, Adhikari B, Sperlich S. Some notes on the economic assessment of land degradation. Land Degradation \& Development. 2011;22(2):285-98.

14. Winslow MD, Vogt JV, Thomas RJ, Sommer S, Martius C, Akhtar-Schuster M. Science for improving the monitoring and assessment of dryland degradation. Land Degradation \& Development. 2011;22(2):145-9.

15. FAO. Achieving sustainable gains in agriculture. 2011. 
16. WOCAT. Where the land is greener: Case studies and analysis of soil and water conservation initiatives worldwide. WOCAT/CTA/UNEP/FAO/CDE, 2007.

17. Liniger HP, Mekdaschi Studer R, Hauert C, Gurtner M. Sustainable Land Management in Practice Guidelines and Best Practices for Sub-Saharan Africa. TerrAfrica, World Overview of Conservation Approaches and Technologies (WOCAT) and Food and Agriculture Organization of the United Nations (FAO), 2011.

18. Akhtar-Schuster M, Thomas RJ, Stringer LC, Chasek P, Seely M. Improving the enabling environment to combat land degradation: Institutional, financial, legal and science-policy challenges and solutions. Land Degradation \& Development. 2011;22(2):299-312.

19. Nkonya E, Gerber N, Baumgartner P, Braun JV, De Pinto A, Graw V, et al. The economics of land degradation: Toward an integrated global assessment. Frankfurt, Germany: Peter Lang; 2011.

20. Requier-Desjardins M. The economic costs of desertification: a first survey of some cases in Africa. International Journal of Sustainable Development. 2006;9(2):199 - 209.

21. Adeel Z, Safriel U, Niemeijer D, White R, de Kalbermatten G, Glantz M, et al. Ecosystems and Human Well-being: Desertification Synthesis, a Report of the Millennium Ecosystem Assessment. Washington, DC: World Resources Institute, 2005.

22. Polasky S, Nelson E, Lonsdorf E, Fackler P, Starfield A. Conserving Species in a Working Landscape: Land Use With Biological and Economic Objectives. Ecological Applications. 2005;15(4):1387-401.

23. Nkonya E, Gerber N, Baumgartner P, von Braun J, De Pinto A, Graw V, et al. The Economics of Desertification, Land Degradation, and Drought. Toward an Integrated Global Assessment. 2011 May 2011. Report No.: Contract No.: 150.

24. Millennium Ecosystem Assessment. Ecosystems and Human Well-being: Desertification Synthesis. Washington D.C.: World Resource Institute, 2005. 
25. Dominati E, Patterson M, Mackay A. A framework for classifying and quantifying the natural capital and ecosystem services of soils. Ecological Economics. 2010;69(9):1858-68.

26. Adhikari B, Nadella K. Ecological economics of soil erosion: a review of the current state of knowledge. 2011;1219(1):134-52.

27. Bojö J. The costs of land degradation in Sub-Saharan Africa. Ecological Economics. 1996;16(2):16173.

28. Ferraro PJ, Lawlor K, Mullan KL, Pattanayak SK. Forest Figures: Ecosystem Services Valuation and Policy Evaluation in Developing Countries. Review of Environmental Economics and Policy. 2012;6(1):20-44.

29. Noel S, Soussan J. Economics of Land degradation: Supporting evidence-base decision making. Methodology for assessing costs of degradation and benefits of sustainable land management. 2012.

30. Enters T. Methods for the economic assessment of the on- and off-site impacts of soil erosion. Bangkok: International Board for Soil Research and Management (IBSRAM), The Soil, Water, and Nutrient Management Programme (SWNM), 1998.

31. Bishop J, Allen J. The On-Site Cost of Soil Erosion in Mali. Washington DC: The World Bank, 1989 Contract No.: Environment Working Paper 21.

32. Nelson RA, Dimes JP, Silburn DM, Paningbatan EP, Cramb RA. Erosion/productivity modelling of maize farming in the Philippine uplands: Part II: simulation of alternative farming methods. Agricultural Systems. 1998;58(2):147-63.

33. Alfsen KH, De Franco MA, Glomsrød S, Johnsen T. The cost of soil erosion in Nicaragua. Ecological Economics. 1996;16(2):129-45.

34. Nelson RA, Cramb RA, Mamicpic MA. Erosion/productivity modelling of maize farming in the Philippine uplands: Part III: economic analysis of alternative farming methods. Agricultural Systems. 1998;58(2):165-83. 
35. Sutcliffe JP. Economic Assessment of Land Degradation in the Ethiopian Highlands - A Case Study. Addis Ababa: National Conservation Strategy Secretariat, Ministry of Planning and Economic Development, 1993.

36. Pimentel D, Harvey C, Resosudarmo P, Sinclair K, Kurz D, McNair M, et al. Environmental and Economic Costs of Soil Erosion and Conservation Benefits. Science. 1995;267(5201):1117-23.

37. Norse D, Saigal R. National economic cost of soil erosion-the case of Zimbabwe. Paper prepared for the CIDIE workshop on Environmental Economics and Natural Resource Management in Developing Countries; World Bank, Washington, DC, 22-24 January 1992: FAO, Rome; 1992.

38. Stocking M. The Cost of Soil Erosion in Zimbabwe in Terms of the Loss of Three Major Nutrients. Rome: FAO, 1986.

39. Stoorvogel JJ, Smaling EMA. Assessment of Soil Nutrient Depletion in Sub-Saharan Africa: 19832000. Wageningen, The Netherlands: 1990 Contract No.: Report 28.

40. Hein L. Assessing the costs of land degradation: a case study for the Puentes catchment, southeast Spain. Land Degradation \& Development. 2007;18(6):631-42.

41. Barbier EB. Valuing ecosystem services as productive inputs. Economic Policy. 2007;22(49):177-229.

42. Crosson PR. The on-farm economic costs of erosion. In: Lal R, Blum WEH, Valentin C, Stewart BA, editors. Methods for Assessment of Land Degradation. Boca Raton: CRC; 1997.

43. Ngugi GW, Newton LE, Muasya AM. The Contribution of Forest Products to Dryland Household Economy: The case of Kiang'ombe hill forest, Kenya. Ethnobotany Research \& Applications; Vol 9 (2011). 2011.

44. Antle JM, Diagana B, Stoorvogel JJ, Valdivia RO. Minimum-data analysis of ecosystem service supply in semi-subsistence agricultural systems. Australian Journal of Agricultural and Resource Economics. 2010;54(4):601-17. 
45. Mekuria W, Veldkamp E, Tilahun M, Olschewski R. Economic valuation of land restoration: The case of exclosures established on communal grazing lands in Tigray, Ethiopia. Land Degradation \& Development. 2011;22(3):334-44.

46. King DA, Sinden JA. Influence of Soil Conservation on Farm Land Values. Land Economics. $1988 ; 64(3): 242-55$

47. Sayadi S, González-Roa MC, Calatrava-Requena J. Public preferences for landscape features: The case of agricultural landscape in mountainous Mediterranean areas. Land Use Policy. 2009;26(2):334-44.

48. Birch JC, Newton AC, Aquino CA, Cantarello E, Echeverría C, Kitzberger T, et al. Cost-effectiveness of dryland forest restoration evaluated by spatial analysis of ecosystem services. Proceedings of the National Academy of Sciences. 2010;107(50):21925-30.

49. Crossman ND, Connor JD, Bryan BA, Summers DM, Ginnivan J. Reconfiguring an irrigation landscape to improve provision of ecosystem services. Ecological Economics. 2010;69(5):1031-42.

50. Gascoigne WR, Hoag D, Koontz L, Tangen BA, Shaffer TL, Gleason RA. Valuing ecosystem and economic services across land-use scenarios in the Prairie Pothole Region of the Dakotas, USA. Ecological Economics. 2011;70(10):1715-25.

51. McFadden D. Contingent Valuation and Social Choice. American Journal of Agricultural Economics. 1994;76(4):689-708.

52. Bateman I, Munro A, Rhodes B, Starmer C, Sugden R. Does Part-Whole Bias Exist? An Experimental Investigation. The Economic Journal. 1997;107(441):322-32.

53. Carson R, Flores NE, Hanemann WM. Sequencing and Valuing Public Goods. Journal of Environmental Economics and Management. 1998;36(3):314-23.

54. Hanley N, Schläpfer F, Spurgeon J. Aggregating the benefits of environmental improvements: distance-decay functions for use and non-use values. Journal of Environmental Management. 2003;68(3):297-304. 
55. Hanley N, Wright R, Adamowicz V. Using Choice Experiments to Value the Environment. Environmental and Resource Economics. 1998;11(3):413-28.

56. Tait $P$, Baskaran R, Cullen R, Bicknell K. Valuation of agricultural impacts on rivers and streams using choice modelling: A New Zealand case study. New Zealand Journal of Agricultural Research. 2011;54(3):143-54.

57. Hajkowicz S, Higgins A, Miller C, Marinoni O. Targeting conservation payments to achieve multiple outcomes. Biological Conservation. 2008;141(9):2368-75.

58. Bateman IJ, Jones AP, Lovett AA, Lake IR, Day BH. Applying Geographical Information Systems (GIS) to Environmental and Resource Economics. Environmental and Resource Economics. 2002;22(1):21969.

59. Bateman IJ, Georgiou S, Lake I. The Aggregation of Environmental Benefit Values: A Spatially Sensitive Valuation Function Approach. Centre for Social and Economic Research on the Global Environment (CSERGE), University of East Anglia (UEA), 2005 Contract No.: Report.

60. Naidoo R, Iwamura T. Global-scale mapping of economic benefits from agricultural lands: Implications for conservation priorities. Biological Conservation. 2007;140(1-2):40-9.

61. Norman L, Tallent-Halsell N, Labiosa W, Weber M, McCoy A, Hirschboeck K, et al. Developing an Ecosystem Services Online Decision Support Tool to Assess the Impacts of Climate Change and Urban Growth in the Santa Cruz Watershed; Where We Live, Work, and Play. Sustainability. 2010;2(7):204469.

62. Rolfe J, Windle J. Testing for differences in benefit transfer values between state and regional frameworks. Australian Journal of Agricultural and Resource Economics. 2008;52(2):149-68.

63. Lovett AA, Brainard JS, Bateman IJ. Improving Benefit Transfer Demand Functions: A GIS Approach. Journal of Environmental Management. 1997;51(4):373-89. 
64. Moeltner K, Boyle KJ, Paterson RW. Meta-analysis and benefit transfer for resource valuationaddressing classical challenges with Bayesian modeling. Journal of Environmental Economics and Management. 2007;53(2):250-69.

65. Lindhjem H, Navrud S. How reliable are meta-analyses for international benefit transfers? Ecological Economics. 2008;66(2-3):425-35.

66. Pagiola S, von Ritter K, Bishop J. Assessing the Economic Value of Ecosystem Conservation. The World Bank Environment Department, 2004 October. Report No.: Contract No.: 101.

67. Berry L, Olson J, Campbell D. Assessing the extent, cost and impact of land degradation at the national level: findings and lessons learned from seven pilot case studies. Commissioned by Global Mechanism with support from the World Bank. 2003.

68. Scarpa R, Gilbride TJ, Campbell D, Hensher DA. Modelling attribute non-attendance in choice experiments for rural landscape valuation. European Review of Agricultural Economics. 2009;36(2):151-74.

69. Balcombe K, Fraser I. A general treatment of 'don't know' responses from choice experiments. European Review of Agricultural Economics. 2011.

70. Kumar P. Capacity constraints in operationalisation of payment for ecosystem services (PES) in India: Evidence from land degradation. Land Degradation \& Development. 2011;22(4):432-43.

71. Chaudhry P, Singh B, Tewari VP. Non-market economic valuation in developing countries: Role of participant observation method in CVM analysis. Journal of Forest Economics. 2007;13(4):259-75.

72. Vouligny É, Domon G, Ruiz J. An assessment of ordinary landscapes by an expert and by its residents: Landscape values in areas of intensive agricultural use. Land Use Policy. 2009;26(4):890-900.

73. Mangham LJ, Hanson K, McPake B. How to do (or not to do) ... Designing a discrete choice experiment for application in a low-income country. Health Policy and Planning. 2009;24(2):151-8. 
74. Mekonnen A, Yesuf M, Carlsson F, Köhlin G. Farmers' Choice between Public Goods and Agricultural Extension Packages in Ethiopia: A Stated Preference Analysis. In: Bennett J, Birol E, editors. Choice experiments in developing countries: implementation, challenges and policy implications: Edward Elgar; 2010. p. 189-204.

75. Bennett J, Birol E. Choice experiments in developing countries: implementation, challenges and policy implications: Edward Elgar; 2010. 


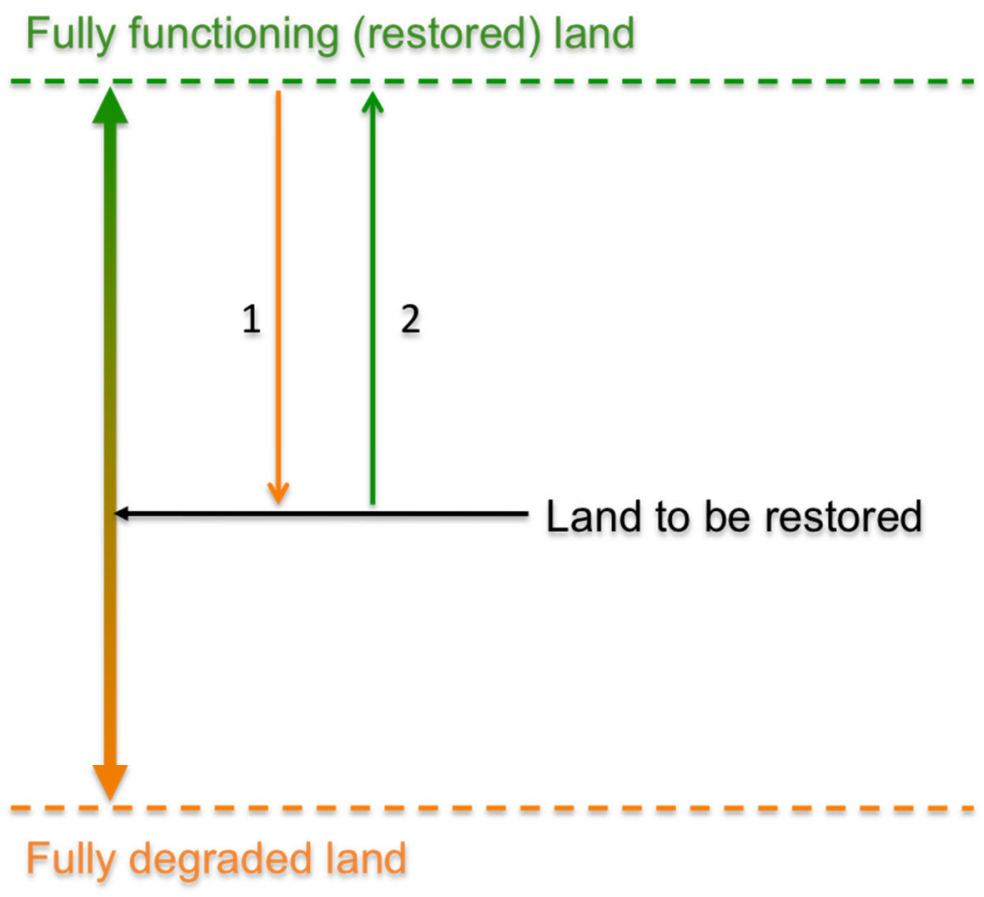

Figure 1: Continuum of land states between fully functioning and fully degraded land, and the relationship between the costs of land degradation and the potential benefits from land restoration. Arrow 1 corresponds to the costs of land degradation and Arrow 2 corresponds to the potential benefits of land restoration.

Table 1: Types of economic values for each type of ecosystem service (supporting services are represented in italics as they are valued through other services)

\begin{tabular}{|c|c|c|c|c|c|}
\hline \multicolumn{2}{|c|}{$\begin{array}{l}\text { Components of } \\
\text { Total Economic Value }\end{array}$} & $\begin{array}{l}\text { Provisioning } \\
\text { services }\end{array}$ & $\begin{array}{c}\text { Regulating } \\
\text { services }\end{array}$ & $\begin{array}{l}\text { Cultural } \\
\text { services }\end{array}$ & $\begin{array}{l}\text { Supporting } \\
\text { services }\end{array}$ \\
\hline Use & Direct use & $\checkmark$ & $\checkmark$ & $\checkmark$ & \\
\hline value & Indirect use & & $\checkmark$ & $\checkmark$ & $\checkmark$ \\
\hline & Option & $\checkmark$ & $\checkmark$ & & \\
\hline value & $\begin{array}{l}\text { Existence } \\
\text { (Bequest) }\end{array}$ & & & $\checkmark$ & \\
\hline
\end{tabular}


Table 2: Proposed alternative frameworks for estimation of the economic cost of land degradation

\begin{tabular}{|c|c|c|c|c|c|}
\hline & & Provisioning services & Regulating services & Cultural services & Supporting services \\
\hline \multirow{2}{*}{$\begin{array}{l}\text { Use } \\
\text { value }\end{array}$} & Direct use & $\checkmark$ & $\checkmark$ & $\checkmark$ & \multirow[b]{2}{*}{$\checkmark$} \\
\hline & Indirect use & & $\checkmark$ & $\checkmark$ & \\
\hline \multirow{2}{*}{$\begin{array}{l}\text { Non-Use } \\
\text { value }\end{array}$} & Option & $\checkmark$ & $\checkmark$ & & \\
\hline & $\begin{array}{l}\text { Existence } \\
\text { (Bequest) }\end{array}$ & & & $\checkmark$ & \\
\hline \multirow{2}{*}{\multicolumn{2}{|c|}{$\begin{array}{l}\text { Alternative 1: } \\
\text { Total Economic Value as } \\
\text { socially weighted sum of } \\
\text { individually estimated } \\
\text { ecosystem values }\end{array}$}} & $\begin{array}{l}\text { Productivity loss model } \\
\text { (supply-based approach) }\end{array}$ & $\begin{array}{l}\text { Costs of extreme events, } \\
\text { costs of externalities } \\
\text { and carbon storage model } \\
\text { (supply-based approach) }\end{array}$ & $\begin{array}{l}\text { Value of (rural) tourism } \\
\text { (demand-based approach) }\end{array}$ & \multirow[t]{2}{*}{-} \\
\hline & & \multicolumn{3}{|c|}{ Values combined using an aggregation function (social weights) } & \\
\hline \multicolumn{2}{|c|}{$\begin{array}{l}\text { Alternative 2: } \\
\text { Direct estimation of } \\
\text { Total Economic Value }\end{array}$} & \multicolumn{3}{|c|}{$\begin{array}{l}\text { Contingent valuation or choice modelling } \\
\text { (demand-based approach) }\end{array}$} & - \\
\hline
\end{tabular}

